\title{
INFLUENCE OF EXPLOITATION CONDITIONS ON ANTI-SKID PROPERTIES OF TYRES
}

\author{
Janusz POKORSKI, Hubert SAR ${ }^{*}$, Andrzej REŃSKI \\ Institute of Vehicles, Warsaw University of Technology, Poland \\ Received 29 March 2017; revised 8 July 2017; accepted 24 August 2017
}

\begin{abstract}
Tyre-to-road adhesion plays an important role when taking into account transmission of forces between tyres and road surface. It consequently influences vehicle safety. Moreover, it plays a significant role for modelling vehicle motion, which is often applied in the development of automotive active safety systems and in traffic accidents reconstruction. Furthermore, tyre-to-road adhesion properties are dependent on many factors. One of the factors is the type of tyre - summer or winter. This is the reason why it is justified to study the anti-slip properties of summer and winter tyres. This paper shows the method of measuring tyre-to-road adhesion coefficient. It is based on a skid resistance tester SRT-4 that consists of a special dynamometer trailer, towing vehicle and test-measuring equipment. It was designed to be applied in civil/road engineering and further developed. As a result, the SRT-4 system automatically obtains adhesion characteristics, such as the graph of tyre-to-road adhesion coefficient as a function of wheel slip ratio and velocity characteristics of lock-up adhesion coefficient. Results of the study present the above mentioned characteristics for different types of tyres (summer, winter) in different exploitation conditions. Differences between presented characteristics caused by tyre type and conditions of exploitation are shown. For example, for winter tyres we noticed that the peak value of adhesion coefficient was attained for higher values of slip ratio as compared with summer tyres.
\end{abstract}

Keywords: tyre-to-road adhesion, skid resistance tester, traffic safety, accident reconstruction, active safety systems, tyre properties, tyre wet grip index.

\author{
Notations \\ Variables: \\ $\mu$ - adhesion coefficient; \\ $\mu_{0}-$ lock-up adhesion coefficient for longitudinal slip \\ ratio $s=1$; \\ $\mu_{\text {peak }}$ - peak adhesion coefficient; \\ $\omega$ - wheel angular velocity; \\ $\dot{\omega}$ - wheel angular deceleration; \\ $F_{z}$ - vertical force; \\ $W$ - braking force between brake pad and brake disc; \\ $h$ - length on which force $W$ is developed, i.e. between \\ brake pad and brake disc and thereby giving the \\ braking torque; \\ $J$ - wheel mass moment of inertia about its rotational \\ axis; \\ $r$ - tyre radius; \\ $T$ - adhesion (friction) force; \\ $v$ - longitudinal velocity of the vehicle.
}

\section{Abbreviations:}

ABS - Anti-lock Brake System;

ESP - Electronic Stability Program.

\section{Introduction}

Investigation of anti-slip properties of tyres is a very important issue, because the adhesion between tyre and road surface has an impact on the active safety of an automobile as presented by Hac and Bodie (2002), Başlamışlı (2014), Will and Zak (2000), Nam et al. (2015), Li et al. (2012). It also plays an important role when talking about accident reconstruction as presented by Han (2017).

Tyre patterns and properties of rubber such as the hardness and elasticity especially in dependence on the temperature play a significant role in vehicle motion stability and the vehicles ability to steer. The approach to the

${ }^{*}$ Corresponding author. E-mail: hubert.sar@pw.edu.pl 
problem of interaction between tyre and road is described by Ella et al. (2013), Skouvaklis et al. (2012), Higgins et al. (2008), Deng et al. (2013), where indoor tests of tyres are presented. They give us an active insight and an extension into further development. The main advantage of such tests are that they are done under stable conditions and results are repeated which is represented tribologically. An interesting method of investigating safety of a vehicle in curvilinear motion is described by Parczewski and Wnęk (2015), where a physical model scaled 1:5 equipped with all necessary sensors is presented. The advantage of this method, contrary to a full-size vehicle, is that it does not require a lot of space to perform road tests. Another method to solve the problem of tyre-road adhesion is by numerical analysis using the finite element method applied by Choi et al. (2012), or by using the brush model of tyre pattern as presented by Heinrich and Klüppel (2008). In one of the papers, Pinnington (2009) and Persson (1998) explain a methodology of simulating the interaction between tyre and road surface characterized by different structure and stochastic unevenness. All the above-mentioned approaches are discussed by Besdo et al. (2010). Farroni (2016) describes the interaction between tyre and road and also elaborates on the effect of factors such as temperature field. Every time numerical models applications are discussed, their parameters should be identified through the comparison to the experiments on real object.

Another solution for tyre-road adhesion coefficient calculation is by performing road tests. Firstly, Zhao et al. (2016) describes an approach based on road tests of an automobile for different driving conditions. This way of obtaining adhesion coefficient between tyre and road is rather an estimation and the method is therefore indirect. Another indirect method of estimating tyre-road adhesion coefficient is presented by Patel et al. (2008), where the adhesion coefficient is obtained on the basis of a braking manoeuvre. Another example is shown by Sjahdanulirwan (1993), where only simple measurements are needed with low number of input data to identify the tyreto-road adhesion. Similar approach is presented by Enisz et al. (2015), where the adhesion coefficient is obtained on the basis of road tests of an automobile through Kalman filtering of measured signals.

Nevertheless, a direct method of adhesion coefficient measurement is the best solution, of course, if it is available. Majority of devices applied in adhesion coefficient measurement was developed for the needs of civil engineering, in particular road surface diagnostics, which plays an important role in traffic safety. This is the reason, why these systems are usually able to obtain adhesion coefficient $\mu$ only for a constant value of longitudinal slip ratio $s$, because they are used in road surface diagnostics, for example (Radó 1994). However, there are some exceptions, where a full adhesion characteristic is obtained, for example Polish SRT-4 system (Pokorski et al. 2015) and German PETRA measuring system (Klempau 2001). However, only SRT-4 system is able to obtain adhesion characteristic $\mu(s)$ automatically in single braking test. The full adhesion characteristic $\mu(s)$ gives more information in the context of automotive active safety systems, especially ABS.

The difference of anti-slip properties between summer (normal) and winter (snow) tyres is the object of discussion when to swap tyres. Very often, it can be heard that it should be below $7^{\circ} \mathrm{C}$. The aim of the article is to check whether such opinion is justified. Moreover, there is another popular opinion that a winter tyre is made of more elastic rubber compared to a summer tyre. The Authors of the paper are expecting the differences in adhesion characteristics $\mu(s)$, not only in the context of maximum values of adhesion coefficient, but also looking at possible differences between the values of longitudinal slip for which the peak adhesion coefficient is reached.

Investigation of wheel dynamics is rather a complex issue. It is relatively simple to investigate normal reaction forces, as presented by Makowski and Knap (2014), for the case of a tested automobile, where these forces are measured through the measurement of suspension deflection and knowledge of its stiffness. However, it is much more complicated to perform measurements of longitudinal tangential forces on the patch between tyre and road.

\section{Description of the measurement system}

The goal of the performed experiments was to show how the various conditions influence the tyre-road adhesion properties. Especially, the value of the coefficient of adhesion for summer and winter tyres for a vehicle driving on pure asphalt or snow under various temperature conditions were studied. The study was based on the performing experiments for measuring friction force that was developed between the tyre and the road surface while braking. Experiment for calculating the friction force was through a SRT-4 (skid resistance tester) measurement system depicted in Figure 1. The system described in detail by Pokorski et al. (2015), consists of a dynamometer trailer and a towing vehicle. Figure $1 \mathrm{~b}$ presents the kinematic schema of a dynamometer trailer.

Suitably arranged structure of the trailer and testmeasuring system makes it possible to adjust braking torque that is acting on the wheel of a trailer (presented additionally in Figure 2) and thus record the signals required for determining the friction force between the wheel and the road surface.

The trailer is equipped with a longitudinal double wishbone suspension. This type of suspension guarantees that when the wheel is braked, then there is no influence of the braking torque on the value of normal reaction force between road and wheel.

The important feature of the presented measuring system (SRT-4) is the ability to obtain the adhesion characteristic - the coefficient of adhesion as a function of the wheel longitudinal slip as a result of recording one (single) braking of the measuring wheel on the chosen section of the road surface. Applied European testing devices require 
multiple attempts to override the test section with the slip ratio values being changed, for example German PETRA device (Klempau 2001). One of the aims of this study is to present the results of the adhesion characteristics obtained using the original innovative measuring system (dynamometer trailer) for a possible comparison (but not in this article) with traditional, time-consuming and costly methods. Another aim of the study was to present the characteristics of adhesion (in different road conditions) obtained by means of the innovative measuring set.

\section{Description of the methodology used}

The system presented in Figures 1 and 2 is integrated with a data acquisition and processing system to enable automatic determination of the full adhesion characteristics on the basis of one braking attempt.

Figure 3 shows the signals that are measured during braking test using dynamometer trailer in time domain. Each iteration of braking lasts for approximately $2 \mathrm{~s}$. The braking torque applied to the brake disc (1) generates a friction force between the wheel and the road surface (3) and thereby causes a reduction in the rotational speed of the wheels (2).

\subsection{Obtaining the adhesion coefficient}

The adhesion coefficient $\mu$ represented by Equation (1) can be summated as the ratio of the adhesion (friction) force $T$ and the vertical force $F_{z}$ (these forces are presented in Figure $1 b)$ :

$$
\mu=\frac{T}{F_{z}} .
$$

The static normal load of the measurement wheel (the vertical force $F_{z}$ ) of the dynamometer trailer equalled during the investigation $3.5 \mathrm{kN}$. The dynamic changes of this force varied $\pm 5 \%$ around $3.5 \mathrm{kN}$ value of the static normal load. a)
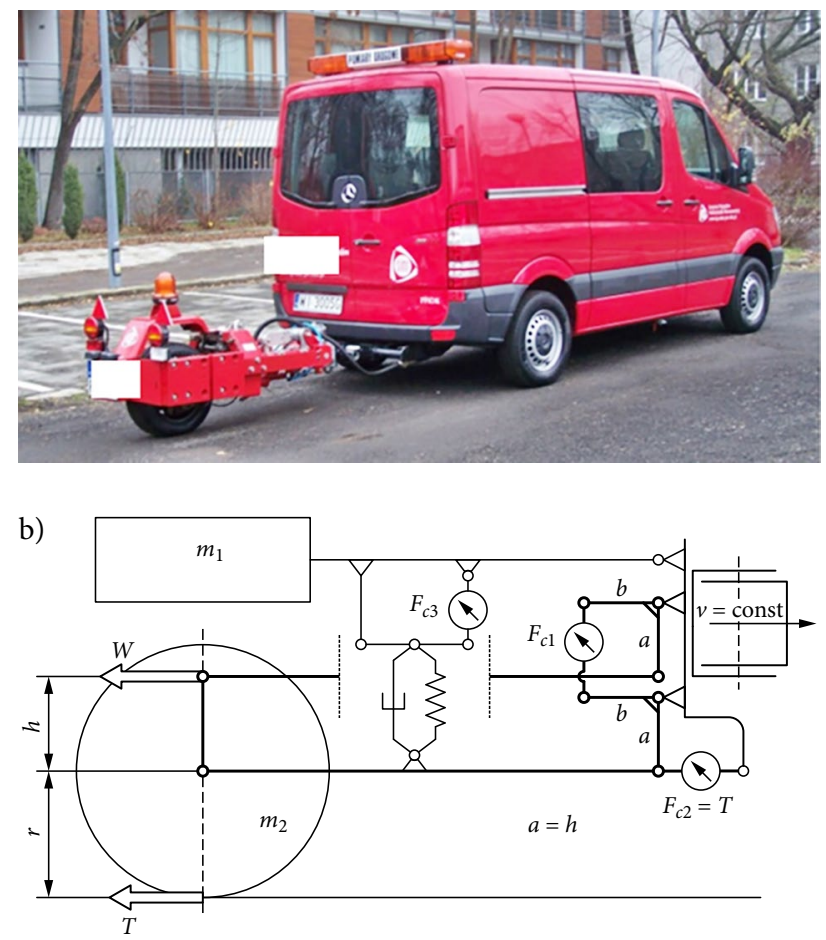

Figure 1. Fourth generation of skid resistance tester SRT-4: a - a photo of towing vehicle and dynamometer trailer; b - kinematic schema of dynamometer trailer with double wishbone suspension

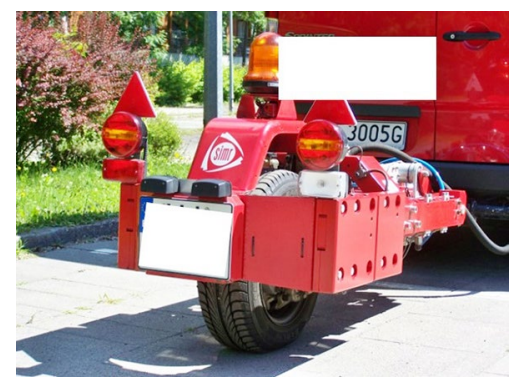

Figure 2. Single-wheel dynamometer trailer

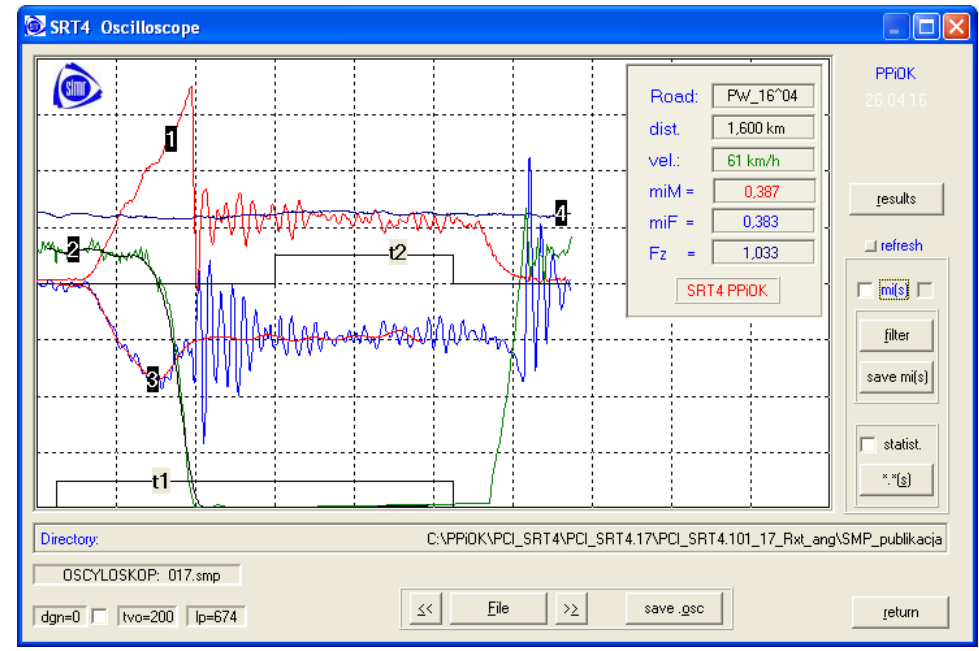

Figure 3. Dynamometer trailer measurement signals: 1 - wheel velocity; 2 - braking torque; 3 - wheel friction force; 4 - wheel normal load 
Longitudinal slip $s$ of the wheel while braking is denoted by Equation (2) and expressed in percentages:

$$
s=\frac{v-r \cdot \omega}{v} \cdot 100 \% .
$$

For testing, the towing vehicle is moving at a constant velocity and the measuring wheel of the dynamometer trailer is braked until it locks. Moreover, it is possible to make experiments also for wet conditions, because the skid resistance tester is equipped with a system that pours the water behind the measurement wheel. For the control valves closed, it is of course possible to perform the investigation on a dry road surface or on a snowy road.

The suspension system of the trailer is based on a double wishbone system, which minimizes the influence of the trailer suspension kinematics on a longitudinal tangential force.

Adhesion coefficient is measured by analysing the rapid increase in braking force $W$ to create wheel lock. Equilibrium equation of the torque on a wheel that is being braked is shown by Equation (3):

$$
W \cdot h=T \cdot r+J \cdot \dot{\omega} .
$$

As we know that for the wheel to lockup its angular velocity is $\omega=0$. Therefore, the dependence between braking force and friction force is represented by Equation (4):

$$
T=\frac{h}{r} \cdot W .
$$

The described procedure below helps to compute the value of the adhesion coefficient, which is supported by the signal values obtained from the mounted force sensors $\left(F_{z}, T\right.$ and $\left.W\right)$ in two different manners:

- applying friction force signal $T$ (Equation (5)):

$$
\mu_{T}=\frac{T}{F_{z}} \text {; }
$$

- by braking force $W$ (Equation (6)):

$$
\mu_{W}=\frac{W \cdot h}{F_{z} \cdot r} .
$$

In addition, by braking the dynamometer trailer we analyse characteristics such as frictional force and the rotational velocity of a wheel (for constant velocity $v$ of a vehicle - see Figure 1b) and thereby obtain characteristic $\mu(s)$ as the dependence between tyre-to-road adhesion and wheel slip. They were obtained for non-steady-state driving conditions for the time interval $t_{1}$ (see the screen of the oscilloscope in Figure 3 ) and for constant velocity $v$ equal to the velocity of the towing vehicle (Wambold et al. 1995).

Also the averaged friction force values in the time interval $t_{2}$ (when the wheel is completely locked) for varying sliding velocities $v$ of the wheel allow to make the so-called velocity characteristics $\mu_{0}(v)$ as presented in Section 3 and are widely used in road engineering.

\subsection{Filtration of the measured signals and the adhesion characteristics approximation}

The characteristics $\mu(s)$ are presented in Subsections 4.1, 4.2 and 4.3. They were determined by:

- the application of original filtering procedures for the friction force measurement results (curve 3 in Figure 3) and the wheel rotational speed (curve 2 in Figure 3);

- the approximation of the so-obtained, non-smooth adhesion characteristics $\mu(s)$ based on one of the three (optionally chosen by the investigator) commonly used formulas - Pacejka (2012), Dugoff et al. (1970), Radó (1994).

The effect of filtering the friction force and the wheel rotational speed is shown in Figure 4.

Exemplary adhesion characteristics after the filtration procedure and the approximations are shown in Figure 5.

Figure 6 represents the values of $\mu(s)$. Two values of adhesion coefficient are defined as follows:

- $\mu_{0}$ - lock-up adhesion coefficient for the longitudinal slip ratio $s=1$;

- $\mu_{\text {peak }}$ - peak adhesion coefficient.

The adhesion characteristic is regarded here as the dependence between the adhesion coefficient and the wheel slip as depicted in Figure 6.

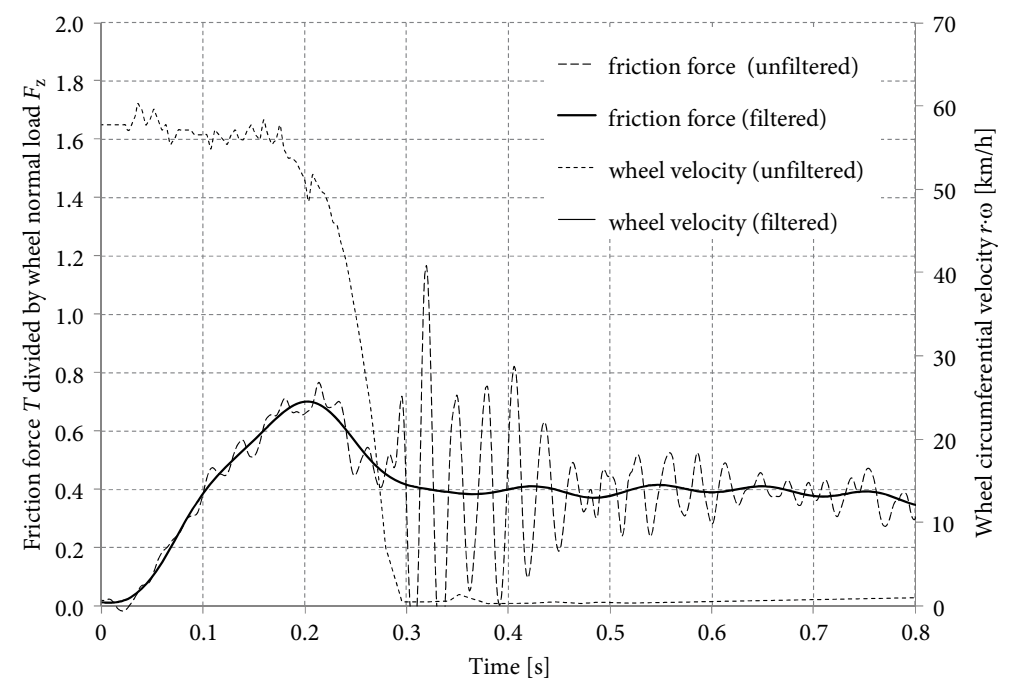

Figure 4. The friction force $T$ divided by the wheel normal load $F_{z}$ and circumferential velocity of the wheel $r \cdot \omega$ after filtration 

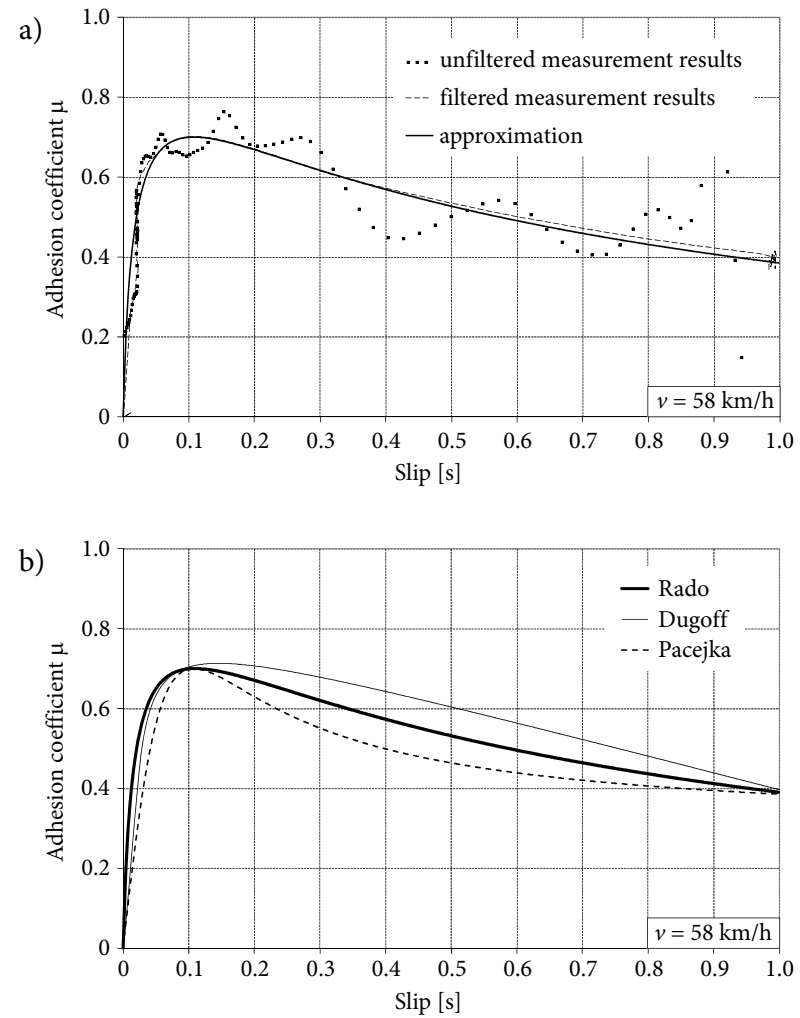

Figure 5. Exemplary $\mu(s)$ characteristics: a - unfiltered, filtered results and one exemplary approximation; $\mathrm{b}$ - approximations using different formulas

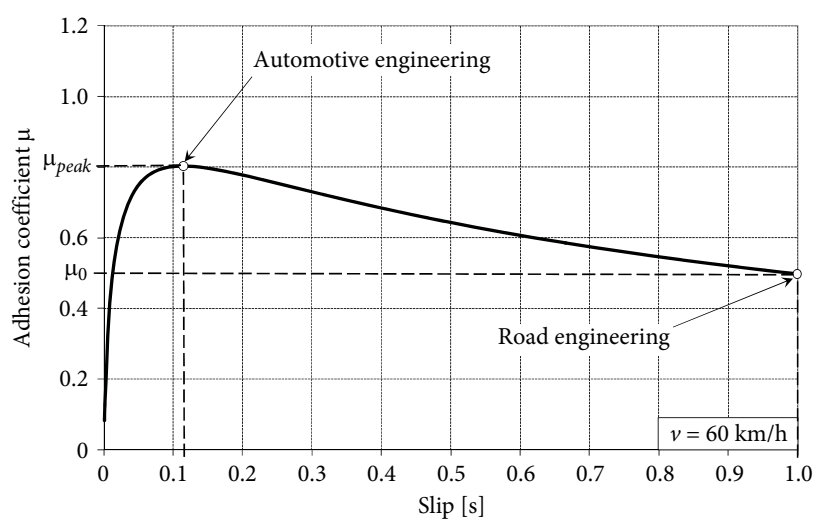

Figure 6. Values of $\mu_{0}$ and $\mu_{\text {peak }}$ based on $\mu(s)$ characteristic

As already mentioned before, lock-up adhesion coefficient $\mu_{0}$ is specific for road engineering, where anti-slip properties of road surfaces are investigated. In this case, special measurement systems are used such as dynamometer trailers.

In case of automotive engineering, where active safety of an automobile is investigated, the peak adhesion coefficient $\mu_{\text {peak }}$ is taken into account, which depends on the value of slip of the wheel. Determining two characteristic points on the adhesion characteristic is possible based on single braking (see also Figure 3).

The results shown in this article are the continuation of the work presented by Pokorski et al. (2012).

\subsection{The object of the research}

The following tyres of size 185/65 R14 and the inflation pressure $0.22 \mathrm{MPa}$ were tested:

- summer tyre of producer 1 (directional tread geometry;

- winter tyre of producer 1 (directional tread geometry);

- summer tyre of producer 2 (asymmetric tread geometry);

- winter tyre of producer 2 (directional tread geometry).

The research was performed for different ambient temperatures of $32,13,2$ and $-15{ }^{\circ} \mathrm{C}$ on a pure asphalt road surface and additionally on snowy road surface. For testing on a snowy road, the air temperature was slightly below $0{ }^{\circ} \mathrm{C}$. This was done both for summer as well as winter tyres, which were manufactured in Europe.

For the temperatures above $0{ }^{\circ} \mathrm{C}$ the experiment was performed both for wet and dry road conditions. It is important to note that the experiment was performed on pure asphalt surfaces of Polish national roads. For subzero conditions the experiments were carried out in Warsaw (Poland) on a cold and dry road. Because of the safety of the measurement, the Authors of the study made some investigations also on snowy road surface, but for lower values of sliding velocities.

\section{Characteristics describing $\mu_{0}$ as a function of $v$}

Figure 7 represents the velocity characteristics $\mu_{0}(v)$ obtained by experimenting on a wet road for different values of sliding velocity $v$ (velocity of a vehicle). The velocity characteristic represents different sliding velocities, so it requires repeating the wheel braking experiments many times (Figure 3). This characteristic also refers to one of four tested tyres.

The vertical dynamic load of the wheel is controlled via the force sensor $\left(F_{c 3}\right.$, Figure $\left.1 \mathrm{~b}\right)$ and in the presented measurements it did not exceed $5 \%$ of the static load.

Figures 8 and 9 represent the characteristics $\mu_{0}(v)$ for ambient temperatures 2 and $13{ }^{\circ} \mathrm{C}$ while driving on a wet road. Here, the summer as well as the winter tyres were analysed.

The effect of ambient temperature on adhesion coefficient between tyre and road is small (Figure 8). In fact, this is seen over the entire range of sliding velocities i.e. 30,60 and $90 \mathrm{~km} / \mathrm{h}$ and is independent from the tyre type (summer or winter).

Characteristically, even for the temperatures close to $0{ }^{\circ} \mathrm{C}$ (Figure 9), summer tyres are characterized by higher forces of friction as compared to winter tyres. This can be observed irrespective of the tyre manufacturer.

The measurement results presented here can be obtained using classic European measuring systems commonly used in road engineering. However, these sets are not able to determine the full adhesion characteristics as easily as the SRT-4 system (see Section 4). 


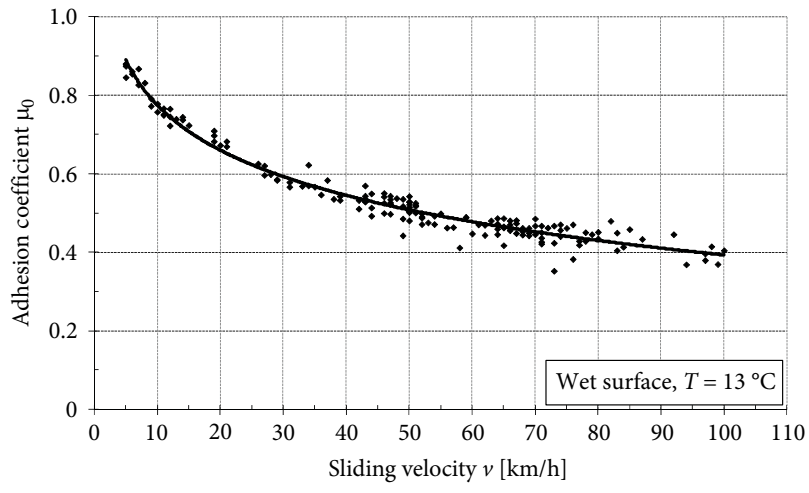

Figure 7. Exemplary velocity characteristic $\mu_{0}(v)$

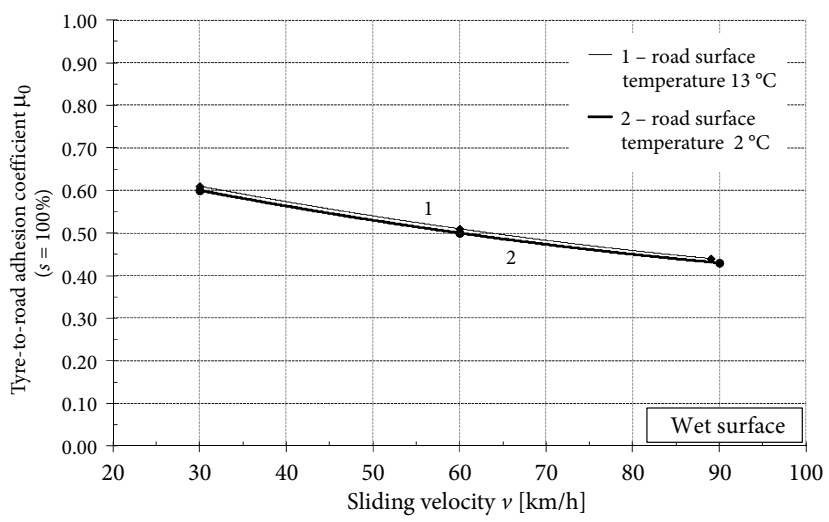

Figure 8 . Velocity characteristics $\mu_{0}(v)$ for different ambient temperatures

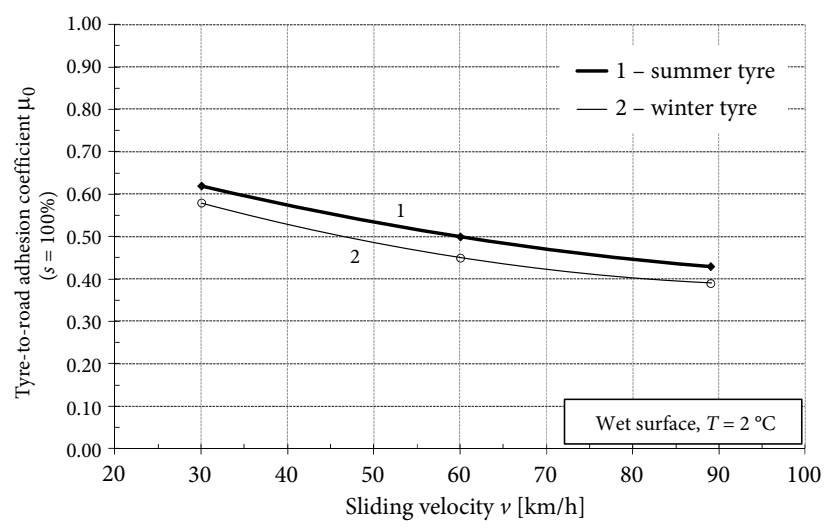

Figure 9. Velocity characteristics: comparison of summer and winter tyres

\section{Adhesion characteristics $\mu(s)$ obtained in different weather conditions}

\subsection{Adhesion characteristics $\mu(s)$ for wet asphalt road surface and ambient temperature above $0{ }^{\circ} \mathrm{C}$}

Figures $10-15$ show the characteristics $\mu(s)$ when temperature of the air rises above zero $\left(32,13\right.$ and $\left.2{ }^{\circ} \mathrm{C}\right)$.

Peak adhesion coefficient is regarded as the maximum adhesion coefficient read from the curve of adhesion characteristic. It was found that peak adhesion coefficient in

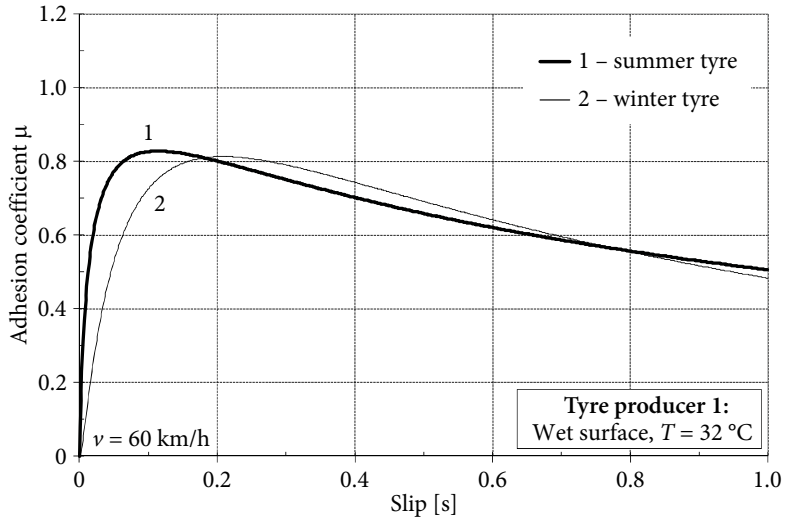

Figure 10. Adhesion characteristics $\mu(s)$ for summer and winter tyres (ambient temperature $32{ }^{\circ} \mathrm{C}$, producer 1 )

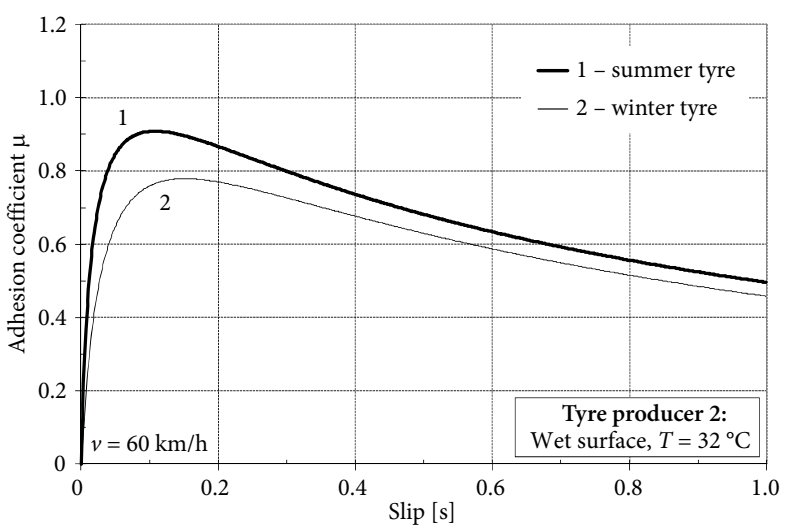

Figure 11. Adhesion characteristics $\mu(s)$ for summer and winter tyres (ambient temperature $32{ }^{\circ} \mathrm{C}$, tyre producer 2 )

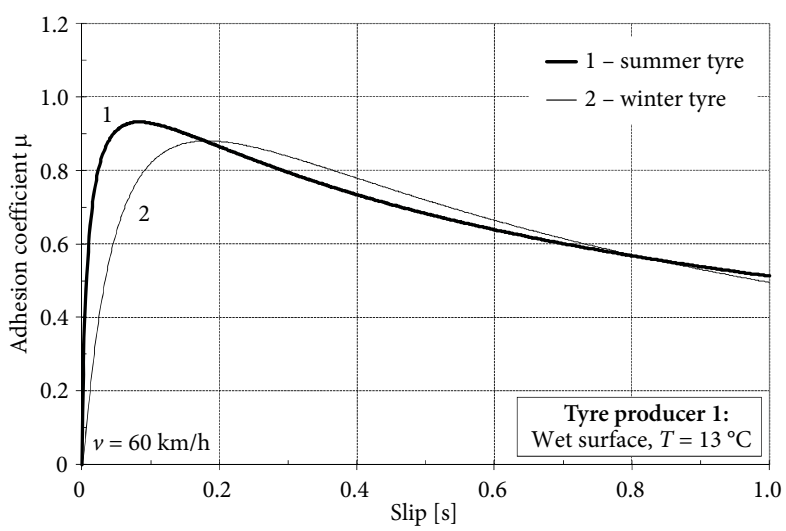

Figure 12. Adhesion characteristics $\mu(s)$ for summer and winter tyres (ambient temperature $13{ }^{\circ} \mathrm{C}$, tyre producer 1 )

the case of winter tyres occurs at significantly higher slip ratio values as compared to summer tyres (Tables 1-6). The reason for this may be the fact that rubber of winter tyres has a higher range of elasticity as compared to summer tyres. In addition, the values of peak adhesion coefficient are higher for summer tyres when considering the temperatures above zero $\left(32,13\right.$ and $\left.2{ }^{\circ} \mathrm{C}\right)$. The adhesion characteristics obtained for the temperatures above zero show that the coefficient $\mu$ for a summer tyre is higher compared to a winter tyre for the whole slip ratio range. 


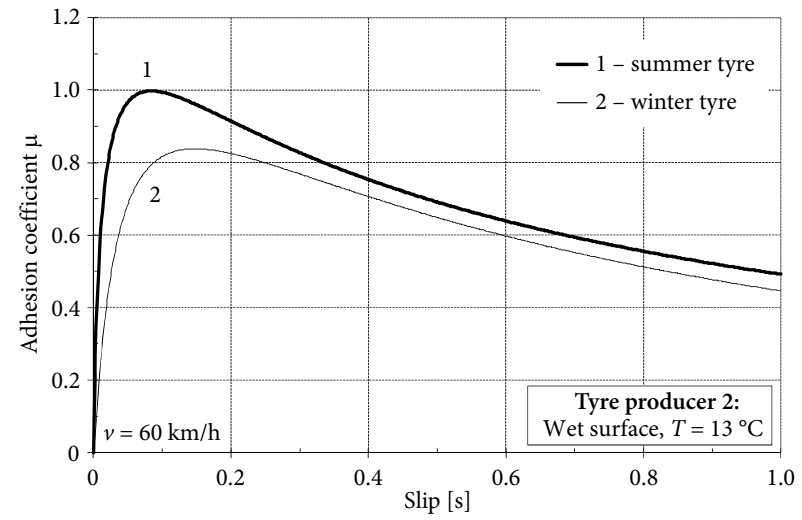

Figure 13. Adhesion characteristics $\mu(s)$ for summer and winter tyres (ambient temperature $13{ }^{\circ} \mathrm{C}$, tyre producer 2 )



Figure 14. Adhesion characteristics $\mu(s)$ for summer and winter tyres (ambient temperature $2{ }^{\circ} \mathrm{C}$, tyre producer 1 )

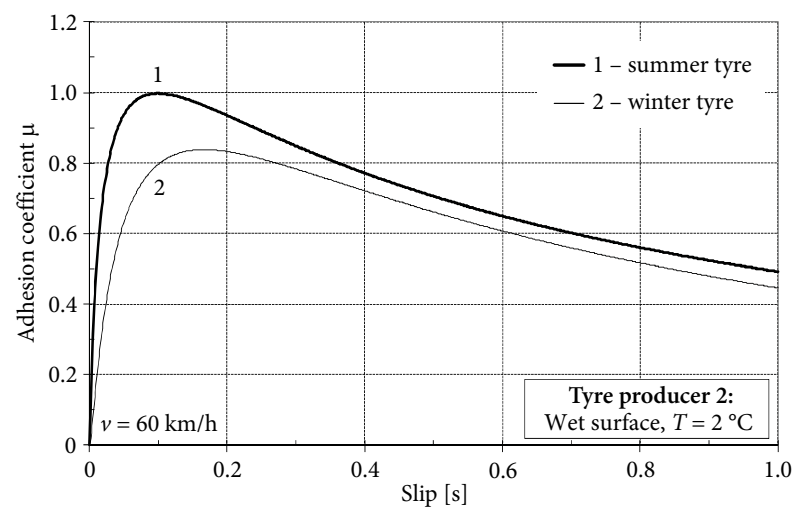

Figure 15. Adhesion characteristics $\mu(s)$ for summer and winter tyres (ambient temperature $2{ }^{\circ} \mathrm{C}$, tyre producer 2 )

Table 1. Differences in slip referring to $\mu_{\text {peak }}$ adhesion coefficient (tyre producer 1 , wet surface, $v=60 \mathrm{~km} / \mathrm{h}, T=32{ }^{\circ} \mathrm{C}$ )

\begin{tabular}{|l|c|c|c|}
\cline { 2 - 4 } \multicolumn{1}{c|}{} & $\mu_{\text {peak }}$ & $s_{\text {peak }}$ & $\mu_{0}$ \\
\hline Summer tyre & 0.83 & 0.11 & 0.51 \\
\hline Winter tyre & 0.81 & 0.21 & 0.48 \\
\hline
\end{tabular}

Table 2. Differences in slip referring to $\mu_{\text {peak }}$ adhesion coefficient (tyre producer 2, wet surface, $v=60 \mathrm{~km} / \mathrm{h}, T=32{ }^{\circ} \mathrm{C}$ )

\begin{tabular}{|l|c|c|c|}
\cline { 2 - 4 } \multicolumn{1}{c|}{} & $\mu_{\text {peak }}$ & $s_{\text {peak }}$ & $\mu_{0}$ \\
\hline Summer tyre & 0.91 & 0.11 & 0.50 \\
\hline Winter tyre & 0.78 & 0.15 & 0.46 \\
\hline
\end{tabular}

Table 3. Differences in slip referring to $\mu_{\text {peak }}$ adhesion coefficient (tyre producer 1 , wet surface, $v=60 \mathrm{~km} / \mathrm{h}, T=13{ }^{\circ} \mathrm{C}$ )

\begin{tabular}{|l|c|c|c|}
\cline { 2 - 4 } \multicolumn{1}{c|}{} & $\mu_{\text {peak }}$ & $s_{\text {peak }}$ & $\mu_{0}$ \\
\hline Summer tyre & 0.93 & 0.08 & 0.51 \\
\hline Winter tyre & 0.88 & 0.18 & 0.50 \\
\hline
\end{tabular}

Table 4. Differences in slip referring to $\mu_{\text {peak }}$ adhesion coefficient (tyre producer 2 , wet surface, $v=60 \mathrm{~km} / \mathrm{h}, T=13^{\circ} \mathrm{C}$ )

\begin{tabular}{|l|c|c|c|}
\cline { 2 - 4 } \multicolumn{1}{c|}{} & $\mu_{\text {peak }}$ & $s_{\text {peak }}$ & $\mu_{0}$ \\
\hline Summer tyre & 1.00 & 0.08 & 0.50 \\
\hline Winter tyre & 0.84 & 0.15 & 0.45 \\
\hline
\end{tabular}

Table 5. Differences in slip referring to $\mu_{\text {peak }}$ adhesion coefficient (tyre producer 1 , wet surface, $v=60 \mathrm{~km} / \mathrm{h}, T=2{ }^{\circ} \mathrm{C}$ )

\begin{tabular}{|l|c|c|c|}
\cline { 2 - 4 } \multicolumn{1}{c|}{} & $\mu_{\text {peak }}$ & $s_{\text {peak }}$ & $\mu_{0}$ \\
\hline Summer tyre & 0.93 & 0.09 & 0.51 \\
\hline Winter tyre & 0.88 & 0.19 & 0.50 \\
\hline
\end{tabular}

Table 6. Differences in slip referring to $\mu_{\text {peak }}$ adhesion coefficient (tyre producer 2 , wet surface, $v=60 \mathrm{~km} / \mathrm{h}, T=2{ }^{\circ} \mathrm{C}$ )

\begin{tabular}{|l|c|c|c|}
\cline { 2 - 4 } \multicolumn{1}{c|}{} & $\mu_{\text {peak }}$ & $s_{\text {peak }}$ & $\mu_{0}$ \\
\hline Summer tyre & 1.00 & 0.10 & 0.49 \\
\hline Winter tyre & 0.84 & 0.17 & 0.45 \\
\hline
\end{tabular}

\subsection{Adhesion characteristics $\mu(s)$ for sub-zero temperature and dry asphalt road surface}

Due to traffic safety and a risk of freezing of trailer control valves, the experiments were performed only on dry asphalt in Warsaw (Poland).

It can be seen that for low temperatures of about $-15^{\circ} \mathrm{C}$, the characteristic $\mu(s)$ in case of winter tyres shows a higher value for the entire range of slip ratio $s$. It is depicted by Figures 16 and 17, and additionally depicted in Tables 7 and 8.

In case of the winter tyre - producer 1 (Figure 16), there can be seen the value of the peak adhesion coefficient, which is higher than 1.0. The reason of this is possibly the micro unevenness of the road. A tyre tread somehow meshes with an unevenness of the road. This increases the adhesion coefficient above the value that results from the normal load of the wheel. It needs to be highlighted that some tyres are able to get a very high adhesion coefficient for optimal slip ratio. Some surfaces (for example a sintered (calcined) bauxite) under wet conditions have a coefficient of adhesion greater than 1.2. A sintered bauxite (Woodward, Friel 2017) is an extremely durable skid resistant aggregate, which is used in high friction surfacing. The peak adhesion coefficient higher than 1.0 is also observed in the work performed by Singh and Taheri (2015).

It has to be emphasized that the results shown in Figures 16 and 17 relate to the measurements on dry, clean surfaces at negative temperatures, unlike all the previous wet surfaces at positive temperatures. 


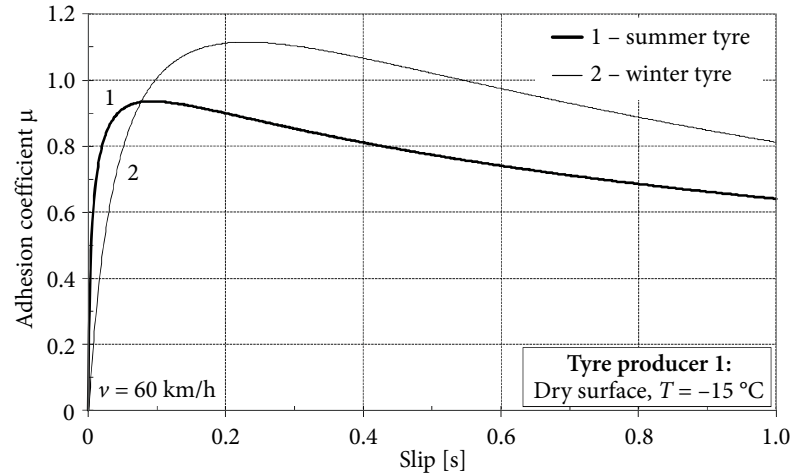

Figure 16. Adhesion characteristics $\mu(s)$ for summer and winter tyres (ambient temperature $-15^{\circ} \mathrm{C}$, tyre producer 1 )

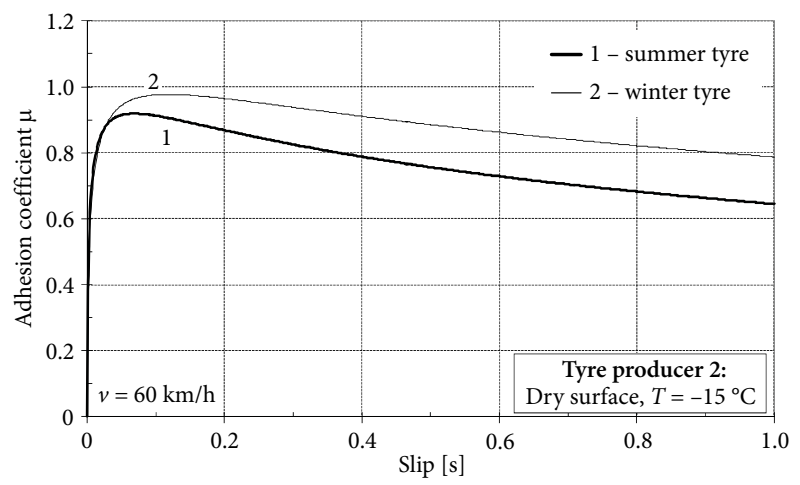

Figure 17. Adhesion characteristics $\mu(s)$ for summer and winter tyres (ambient temperature $-15{ }^{\circ} \mathrm{C}$, tyre producer 2 )

Table 7. Differences in slip referring to $\mu_{\text {peak }}$ adhesion coefficient (tyre producer 1 , wet surface, $v=60 \mathrm{~km} / \mathrm{h}, T=-15^{\circ} \mathrm{C}$ )

\begin{tabular}{|l|c|c|c|}
\cline { 2 - 4 } \multicolumn{1}{c|}{} & $\mu_{\text {peak }}$ & $s_{\text {peak }}$ & $\mu_{0}$ \\
\hline Summer tyre & 0.94 & 0.09 & 0.64 \\
\hline Winter tyre & 1.12 & 0.23 & 0.81 \\
\hline
\end{tabular}

Table 8. Differences in slip referring to $\mu_{\text {peak }}$ adhesion coefficient (tyre producer 2, wet surface, $v=60 \mathrm{~km} / \mathrm{h}, T=-15^{\circ} \mathrm{C}$ )

\begin{tabular}{|l|c|c|c|}
\cline { 2 - 4 } \multicolumn{1}{c|}{} & $\mu_{\text {peak }}$ & $s_{\text {peak }}$ & $\mu_{0}$ \\
\hline Summer tyre & 0.92 & 0.12 & 0.65 \\
\hline Winter tyre & 0.98 & 0.23 & 0.79 \\
\hline
\end{tabular}

\subsection{Adhesion characteristics $\mu(s)$ for snowy road surface and sub-zero ambient temperature}

For comparative aims, measurements of adhesion on snow using SRT-4 system were performed.

Adhesion characteristics of investigated tyres for selected attempts are presented in Figures 18 and 19, and additionally represented by Tables 9 and 10. On the basis of presented results, it can be stated that winter tyres are characterized by a higher adhesion coefficient on snowy road surfaces with ambient temperature slightly below $0{ }^{\circ} \mathrm{C}$ compared to summer tyres, especially in case of tyre producer 1 .

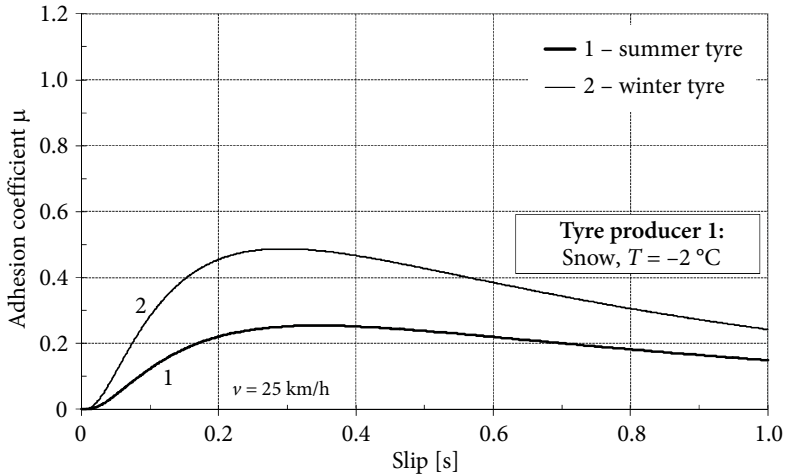

Figure 18. Adhesion characteristics $\mu(s)$ for summer and winter tyres (snowy road surface, tyre producer 1 )

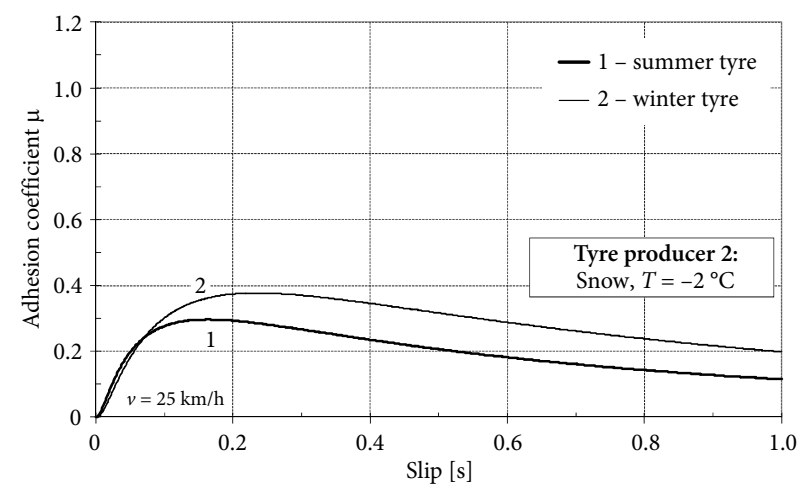

Figure 19. Adhesion characteristics $\mu(s)$ for summer and winter tyres (snowy road surface, tyre producer 2 )

Table 9. Differences in slip referring to $\mu_{\text {peak }}$ adhesion coefficient (tyre producer 1 , snowy surface, $v=25 \mathrm{~km} / \mathrm{h}, T=-2{ }^{\circ} \mathrm{C}$ )

\begin{tabular}{|l|c|c|c|}
\cline { 2 - 4 } \multicolumn{1}{c|}{} & $\mu_{\text {peak }}$ & $s_{\text {peak }}$ & $\mu_{0}$ \\
\hline Summer tyre & 0.26 & 0.35 & 0.15 \\
\hline Winter tyre & 0.48 & 0.30 & 0.25 \\
\hline
\end{tabular}

Table 10. Differences in slip referring to $\mu_{\text {peak }}$ adhesion coefficient (tyre producer 2, snowy surface, $v=25 \mathrm{~km} / \mathrm{h}, T=-2{ }^{\circ} \mathrm{C}$ )

\begin{tabular}{|l|c|c|c|}
\cline { 2 - 4 } \multicolumn{1}{c|}{} & $\mu_{\text {peak }}$ & $s_{\text {peak }}$ & $\mu_{0}$ \\
\hline Summer tyre & 0.29 & 0.17 & 0.12 \\
\hline Winter tyre & 0.37 & 0.23 & 0.20 \\
\hline
\end{tabular}

\section{Conclusions}

The knowledge of tyre-to-road interaction is very needed for automotive technology. On the one hand, one of the new EU directives - Regulation (EC) No 1222/2009 (EC 2009) requires labelling for all new tyres. Among others, the label contains the information about tyre-to-road adhesion. It means that the basic information about tyre-to-road adhesion is given. However, this information is targeted mainly to the customer, which makes it useless to make a simulation concerning the motion of a vehicle. Therefore, some further information is necessary, because the tyreto-road adhesion coefficient depends for example on the 
longitudinal slip and the sliding velocity. Furthermore, it strongly depends on weather conditions and road surface. Based on thorough investigation of the tyre-to-road adhesion, including different types of tyres (summer, winter), we presented the results of the adhesion measurement results. This study gives a valuable information for automotive experts how tyre-to-road adhesion properties vary according to weather conditions and a type of a tyre:

1. The innovative measuring system used in the presented research is able to determine the adhesion characteristics $\mu(s)$ on the basis of single braking test of the measurement wheel. Comparative to some extend European measuring devices are measuring the adhesion properties for the fixed value of slip. The authorial software responsible for the measurement processing is obtaining the $\mu(s)$ characteristics after automatic filtration of the measured signals. This is the reason why the adhesion characteristics are so smooth;

2. The research was conducted on clean asphalt road surfaces in the range of the temperatures from -15 to $+32{ }^{\circ} \mathrm{C}$. For temperatures above zero summer tyres are characterized by a higher coefficient $\mu_{0}$ (when a wheel is locked) as compared to winter tyres. The same effect takes place for the temperatures close to zero. Similarly, for the temperatures above zero the peak values of the adhesion coefficient $\mu_{\text {peak }}$ are higher in case of summer tyres. Thus, the deterioration of the anti-slip properties is not observed until the temperature is approximately $7{ }^{\circ} \mathrm{C}$, which is often regarded as decisive when to change from summer to winter tyres;

3. For extreme winter temperatures of $-15{ }^{\circ} \mathrm{C}$ and beyond, the $\mu(s)$ characteristics of winter tyres are characterized by significantly higher value of coefficient $\mu$. This can be observed for the entire range of the longitudinal slip ratio and hence the value of coefficient $\mu_{\text {peak }}$ is higher for winter tyres as compared to summer tyres. Another reason being that winter tyres are made up of a rubber, which has a higher value of elasticity. Certainly, it affects the functioning of such active safety systems such as ABS or ESP as these systems are working closely near the maximum value of adhesion coefficient $\mu_{\text {peak }}$;

4. Additionally, some experiments were made on snow for ambient temperature slightly below $0{ }^{\circ} \mathrm{C}$. The experiments on snow together with the investigation for the ambient temperature $-15^{\circ} \mathrm{C}$ and dry surface clearly show the advantage of using winter tyres.

Additional investigations for winter conditions of snow and ice should be performed in order to validate our measurements. In addition, tyres used for summer, winter as well as all weather conditions from several manufactures should be further analysed for anti-slip properties.

\section{References}

Başlamışl1, S. Ç. 2014. Development of rational tyre models for vehicle dynamics control design and combined vehicle state/parameter estimation, International Journal of Vehicle Design 65(2/3): 144-175. https://doi.org/10.1504/IJVD.2014.060766

Besdo, D.; Heimann, B.; Klüppel, M.; Kröger, M.; Wriggers, P.; Nackenhorst, U. 2010. Elastomere Friction: Theory, Experiment and Simulation. Springer.

https://doi.org/10.1007/978-3-642-10657-6

Choi, J. H.; Cho, J. R.; Woo, J. S.; Kim, K. W. 2012. Numerical investigation of snow traction characteristics of 3-D patterned tire, Journal of Terramechanics 49(2): 81-93.

https://doi.org/10.1016/j.jterra.2012.01.003

Deng, Z.; Qi, Z. T.; Dong, Z.; He, P.; Han, C.; Ren, S. 2013. A road surface identification method for a four in-wheel-motor drive electric vehicle, International Journal of Biomechatronics and Biomedical Robotics 2(2/3/4): 87-92.

https://doi.org/10.1504/IJBBR.2013.058721

Dugoff, H.; Fancher, P. S.; Segel, L. 1970. An analysis of tire traction properties and their influence on vehicle dynamic performance, SAE Technical Paper 700377. https://doi.org/10.4271/700377

EC. 2009. Regulation (EC) No 1222/2009 of the European Parliament and of the Council of 25 November 2009 on the Labelling of Tyres with Respect to Fuel Efficiency and Other Essential Parameters. Available from Internet:

http://data.europa.eu/eli/reg/2009/1222/oj

Ella, S.; Formagne, P.-Y.; Koutsos, V.; Blackford; J. R. 2013. Investigation of rubber friction on snow for tyres, Tribology International 59: 292-301.

https://doi.org/10.1016/j.triboint.2012.01.017

Enisz, K.; Szalay, I.; Kohlrusz, G.; Fodor, D. 2015. Tyre-road friction coefficient estimation based on the discrete-time extended Kalman filter, Proceedings of the Institution of Mechanical Engineers, Part D: Journal of Automobile Engineering 229(9): 1158-1168. https://doi.org/10.1177/0954407014556115

Farroni, F. 2016. T.R.I.C.K. - tire/road interaction characterization \& knowledge - a tool for the evaluation of tire and vehicle performances in outdoor test sessions, Mechanical Systems and Signal Processing 72-73: 808-831.

https://doi.org/10.1016/j.ymssp.2015.11.019

Hac, A.; Bodie, M. O. 2002. Improvements in vehicle handling through integrated control of chassis systems, International Journal of Vehicle Autonomous Systems 1(1): 83-110. https://doi.org/10.1504/IJVAS.2002.001807

Han, I. 2017. Modelling the tyre forces for a simulation analysis of a vehicle accident reconstruction, Proceedings of the Institution of Mechanical Engineers, Part D: Journal of Automobile Engineering 231(1): 16-26. https://doi.org/10.1177/0954407016630449

Heinrich, G.; Klüppel, M. 2008. Rubber friction, tread deformation and tire traction, Wear 265(7-8): 1052-1060.

https://doi.org/10.1016/j.wear.2008.02.016

Higgins, D. D.; Marmo, B. A.; Jeffree, C. E.; Koutsos, V.; Blackford, J. R. 2008. Morphology of ice wear from rubber-ice friction tests and its dependence on temperature and sliding velocity, Wear 265(5-6): 634-644.

https://doi.org/10.1016/j.wear.2007.12.015 
Klempau, F. 2001. Development of a friction prediction system, in 2 nd International Colloquium on Vehicle Tyre Road Interaction, 23 February 2001, Florence, Italy, 1-17.

Li, Y.; Zhang, J.; Guan, X. 2012. Estimation of tyre-road friction coefficient, International Journal of Vehicle Systems Modelling and Testing 7(3): 285-302.

https://doi.org/10.1504/IJVSMT.2012.048942

Makowski, M.; Knap, L. 2014. Reduction of wheel force variations with magnetorheological devices, Journal of Vibration and Control 20(10): 1552-1564.

https://doi.org/10.1177/1077546312472916

Nam, K.; Fujimoto, H.; Hori, Y. 2015. Design of an adaptive sliding mode controller for robust yaw stabilisation of in-wheelmotor-driven electric vehicles, International Journal of Vehicle Design 67(1): 98-113.

https://doi.org/10.1504/IJVD.2015.066474

Pacejka, H. 2012. Tire and Vehicle Dynamics. ButterworthHeinemann. 672 p.

Parczewski, K.; Wnęk, H. 2015. The tyre characteristics of the physical model used to investigate the lateral stability of a vehicle, Proceedings of the Institution of Mechanical Engineers, Part D: Journal of Automobile Engineering 229(10): 14191426. https://doi.org/10.1177/0954407014563734

Patel, N.; Edwards, C.; Spurgeon, S. K. 2008. Tyre-road friction estimation: a comparative study, Proceedings of the Institution of Mechanical Engineers, Part D: Journal of Automobile Engineering 222(12): 2337-2351. https://doi.org/10.1243/09544070JAUTO859

Persson, B. N. J. 1998. On the theory of rubber friction, Surface Science 401(3): 445-454. https://doi.org/10.1016/S0039-6028(98)00051-X

Pinnington, R. J. 2009. Rubber friction on rough and smooth surfaces, Wear 267(9-10): 1653-1664. https://doi.org/10.1016/j.wear.2009.06.011

Pokorski, J.; Reński, A.; Sar, H. 2012. Investigation of adhesion characteristics of different tyre types in different weather conditions, Journal of KONES: Powertrain and Transport 19(3): 363-369. https://doi.org/10.5604/12314005.1138147

Pokorski, J.; Reński, A.; Sar, H. 2015. System for investigation of friction properties of the road surface, The Baltic Journal of Road and Bridge Engineering 10(2): 126-131.

Radó, Z. 1994. A Study of Road Surface Texture and Its Relationship to Friction. PhD Thesis, Pennsylvania State University, US.

Singh, K. B.; Taheri, S. 2015. Estimation of tire-road friction coefficient and its application in chassis control systems, Systems Science \& Control Engineering 3(1): 39-61.

https://doi.org/10.1080/21642583.2014.985804

Sjahdanulirwan, M. 1993. An analytical model for the prediction of tyre-road friction under braking and cornering, International Journal of Vehicle Design 14(1): 78-99.

Skouvaklis, G.; Blackford, J. R.; Koutsos, V. 2012. Friction of rubber on ice: A new machine, influence of rubber properties and sliding parameters, Tribology International 49: 44-52. https://doi.org/10.1016/j.triboint.2011.12.015

Wambold, J. C.; Antle, C.; E.; Henry, J. J.; Radó, Z. 1995. International PIARC Experiment to Compare and Harmonize Texture and Skid Resistance Measurement. Permanent International Association of Road Congresses (PIARC). 423 p.

Will, A. B.; Zak, S. H. 2000. Antilock brake system modelling and fuzzy control, International Journal of Vehicle Design 24(1): 1-18. https://doi.org/10.1504/IJVD.2000.001870

Woodward, D.; Friel, S. 2017. Predicting the wear of high friction surfacing aggregate, Coatings 7(5): 71.

https://doi.org/10.3390/coatings7050071
Zhao, J.; Zhang, J.; Zhu, B. 2016. Coordinative traction control of vehicles based on identification of the tyre-road friction coefficient, Proceedings of the Institution of Mechanical Engineers, Part D: Journal of Automobile Engineering 230(12): 1585-1604. https://doi.org/10.1177/0954407015618041 